Article

\title{
Graphene Oxide-Supported Oxime Palladacycles as Efficient Catalysts for the Suzuki-Miyaura Cross-Coupling Reaction of Aryl Bromides at Room Temperature under Aqueous Conditions
}

\author{
Melania Gómez-Martínez, Alejandro Baeza * and Diego A. Alonso * \\ Departamento de Química Orgánica and Instituto de Síntesis Orgánica (ISO), Facultad de Ciencias, \\ Universidad de Alicante. Apdo. 99, E-03080 Alicante, Spain; melania.gomez@ua.es \\ * Correspondence: alex.baeza@ua.es (A.B.); diego.alonso@ua.es (D.A.A.); \\ Tel.: +34-965-902-888 (A.B.); +34-965-909-841 (D.A.A.)
}

Academic Editor: Ioannis D. Kostas

Received: 25 January 2017; Accepted: 16 March 2017; Published: 22 March 2017

\begin{abstract}
Palladacycles are highly efficient precatalysts in cross-coupling reactions whose immobilization on carbonaceous materials has been hardly studied. Herein, we report a detailed study on the synthesis and characterization of new oxime palladacycle-graphene oxide non-covalent materials along with their catalytic activity in the Suzuki-Miyaura reaction. Catalyst 1-GO, which has been fully characterized by ICP, XPS, TGA, and UV-Vis analyses has been demonstrated to be an efficient catalyst for the Suzuki-Miyaura coupling between aryl bromides and arylboronic acids using very low catalyst loadings ( $0.002 \mathrm{~mol} \%$ of Pd) at room temperature under aqueous conditions.
\end{abstract}

Keywords: graphene oxide; Suzuki-Miyaura coupling; palladacycle; aryl bromide; palladium; aqueous conditions

\section{Introduction}

Palladium-catalyzed cross-coupling reactions occupy a predominant place in the arsenal of synthetic chemists [1-9]. Carbometallated $\mathrm{Pd}(\mathrm{II})$ compounds, especially the highly active palladacycles [10-13], have emerged as very promising catalysts for $\mathrm{C}-\mathrm{C}$ bond forming reactions. These complexes usually involve very low catalyst loadings, minimizing the cost-effective impact of the expensive palladium. However, the product contamination problems associated with this toxic metal have converted the immobilization of this type of well-defined complex into an attractive strategy to develop sustainable catalytic processes. Until now, different palladacycles have been immobilized on inorganic and organic supports through covalent or non-covalent interactions [11,12]. Among them, silica-based supports [14-24], organic polymers [19,25-37], monolithic supports [38], magnetic nanoparticles [39,40], macrocyclic molecules [41], and Montmorillonite [42,43], are the studied systems. Although these catalysts can be generally reused, a progressive deactivation caused by complex degradation is usually observed, with the reaction products generally being vulnerable to palladium contamination [44]. Also, contribution to the catalysis of leached species, from the solid into the solution, is usually observed.

During the last years, carbon-derived materials have been designed as interesting supports for palladium nanoparticles due to their chemical stability as well as large specific surface area. This type of catalyst has been mainly used in the Suzuki-Miyaura cross-coupling reaction [45-62]. However, to the best of our knowledge, only very recently has some attention been paid to the immobilization of palladacycles to graphene materials, with two studies having been reported so far using covalent immobilization strategies [63,64]. 
Very recently, we have shown that palladium nanoparticles (Pd NPs), supported on graphene and reduced graphene oxide, efficiently catalyze the Suzuki-Miyaura coupling between aryl bromides and potassium aryltrifluoroborates under aqueous and low loading conditions $(0.1 \mathrm{~mol} \% \mathrm{Pd})$ employing conventional or microwave heating [65]. Based on the experience and knowledge of our research group with oxime palladacycles as highly efficient precatalysts in cross-coupling reactions [66-68], herein we report a detailed study on the synthesis and characterization of new oxime palladacycle-graphene oxide non-covalent materials along with their catalytic activity in the Suzuki-Miyaura reaction.

\section{Results and Discussion}

We initially chose GO as support for oxime palladacycles 1-3 (Figure 1) since this carbon material shows interesting hydrophilicity and stability properties in liquid phase reactions due to the abundant oxygen-containing functional groups on its surface. A non-covalent immobilization strategy, through hydrogen-bond and $\pi$-stacking interactions between the pre-formed palladacycles and the functionalized carbon support was selected to prepare the new catalytic materials. This approach should integrally preserve the palladacycle structure, avoiding an uncontrolled generation of other $\operatorname{Pd}(\mathrm{II})$ or $\mathrm{Pd}(0)$ species, as demonstrated by other authors when using a post-palladation strategy [17]. Furthermore, we expect the carbonaceous support to act as a reservoir and stabilizing medium for the in situ generated Pd NPs, which could extend the catalyst lifetime.

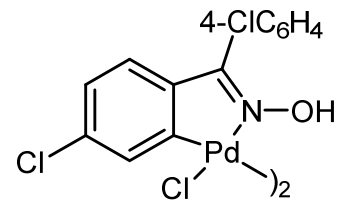

1<smiles></smiles>

2<smiles></smiles>

3

Figure 1. Oxime palladacycles employed in this study.

Preliminary studies on the immobilization of the palladacycles over GO were carried out with complex 1. The preparation procedures tested to obtain the 1-GO catalyst are indicated in Scheme 1. Basically, they consisted of the synthesis of the corresponding oxime palladacycle 1 from $4,4^{\prime}$-dichlorobenzophenone [69] and a subsequent immobilization of this complex over GO [70] in THF or water as solvents (Scheme 1). As depicted, sonication of the palladacycle in the presence of GO for $1 \mathrm{~h}$ (methods B and C) significantly improved the content of the immobilized complex on the carbon surface as determined by Inductively Coupled Plasma Optical Emission Spectrometry ICP-OES, being the highest ( $2 \mathrm{wt} \% \mathrm{Pd}$ ) when using THF as solvent (method B). Finally, following B conditions but starting from 4-hydroxyacetophenone and 1-[4-(2-hydroxyethoxy)phenyl]ethan-1-one, the supported catalysts 2-GO (2.72 wt \% Pd by ICP-OES) and 3-GO (2.98 wt \% Pd by ICP-OES) were also prepared (Scheme 1).

X-ray photoelectron spectroscopy (XPS) was used to analyze the elemental composition of the surface of the different catalysts. Interestingly, XPS analysis of the palladacycles 1-3 and all the supported catalyst batches showed all the binding energies associated with the oxime palladacycle structure (see SI). This point confirmed the stability of the cyclopalladated complexes during the immobilization process to GO. In fact, in the case of the preparation of 1-GO, no structural changes were observed by ${ }^{1} \mathrm{H}-\mathrm{NMR}$ analysis in the eluted palladacycle after the immobilization process (see SI). Generally, none of the prepared catalysts contained palladium oxides or palladium(0) species on their surface according to the XPS analyses. Indeed, in isolated cases we could identify small amounts of the precursor $\mathrm{Li}_{2} \mathrm{PdCl}_{4}$ by XPS analysis, easily removed by simple washings with water. On the other hand, in the case of using water as solvent (method C) for the preparation of 1-GO, we also observed small amounts $(\sim 8 \%)$ of a non-identified oxidized palladium specie ( 336.0 and $341.1 \mathrm{eV}$ by XPS, see SI). 


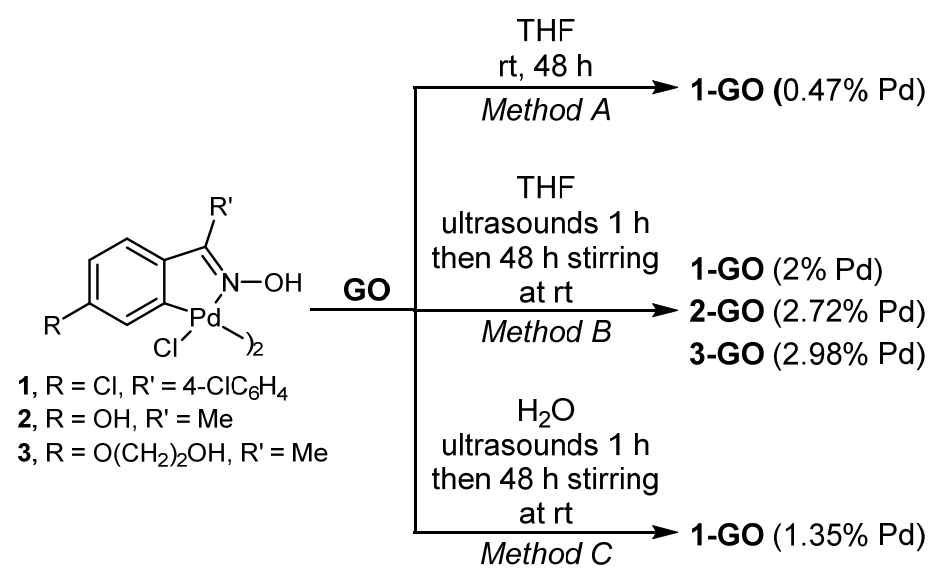

Scheme 1. Synthesis of supported oxime palladacycles.

Thus, performing the palladation reaction using THF as solvent before immobilization onto GO led to the integral cyclopalladated species being supported. In fact, $\operatorname{Pd}(0)$ has been previously detected when anchoring oxime palladacycles to different supports such as, 3-hydroxypropyltriethoxysilylfunctionalized MCM-41 [17] and 3-(aminomethyl)pyridine-functionalized graphene oxide [63].

Figures 2 and 3 show the XPS spectra of $\mathbf{1}$ and 1-GO where the spectroscopic signature of palladium, carbon, oxygen, and nitrogen atoms has been determined [71-73] Regarding palladium (Figure 3a), the Pd3d XPS spectrum for 1 and 1-GO showed the corresponding binding energies at $337.70(3 \mathrm{~d} 5 / 2)$ and $343.02(3 \mathrm{~d} 3 / 2) \mathrm{eV}$ and $337.62(3 \mathrm{~d} 5 / 2)$ and $342.83(3 \mathrm{~d} 3 / 2) \mathrm{eV}$, respectively. These energies were assigned to the $\mathrm{Pd}(\mathrm{II})$ from the oxime palladacycle. On the other hand, O1s XPS analysis for catalyst 1 showed three different components related to the $\mathrm{C}=\mathrm{N}-\mathrm{OH}$ bond at $531.76 \mathrm{eV}$, the $\mathrm{O}-\mathrm{H}$ bond at $533.5 \mathrm{eV}$ and the $\mathrm{C}-\mathrm{O}$ bond at $532.20 \mathrm{eV}$ (Figure $3 \mathrm{~b}$ ). The higher content of the $\mathrm{O}-\mathrm{H}$ and $\mathrm{C}-\mathrm{O}$ groups in 1-GO (532.20 and $533.32 \mathrm{eV}$, respectively) can be associated with the corresponding groups on the graphene oxide surface. The carbonaceous material was also responsible for the higher content of the $\mathrm{C}=\mathrm{C} / \mathrm{C}-\mathrm{H}$ aromatic ring binding energies (284.60 and $286.71 \mathrm{eV})$ in the $\mathrm{C} 1 \mathrm{~s}$ XPS spectrum of 1-GO when compared with $\mathbf{1}$ (Figure 3c). The N1s XPS spectra of $\mathbf{1}$ and 1-GO showed the $\mathrm{N}=\mathrm{C}$ bonding energies at 400.36 and $399.93 \mathrm{eV}$, respectively. Furthermore, the peaks corresponding to the N-Pd moiety appeared at $402.86 \mathrm{eV}$ for 1 and $401.93 \mathrm{eV}$ for 1-GO (Figure 3d). Finally, the Cl2p XPS spectra of 1 was analyzed showing the corresponding binding energies at $198.6 \mathrm{eV}(2 \mathrm{p}), 199.9$ $(2 \mathrm{p} 3 / 2)$ and $200.3 \mathrm{eV}(2 \mathrm{p} 1 / 2)$. These energies were assigned to the $\mathrm{Cl}-\mathrm{Pd}$ bonding energy from the oxime palladacycle 1 . The band at $200.18 \mathrm{eV}$ corresponded to the $2 \mathrm{p} 3 / 2$ aromatic-Cl bonding energy (Figure 3e) [63].
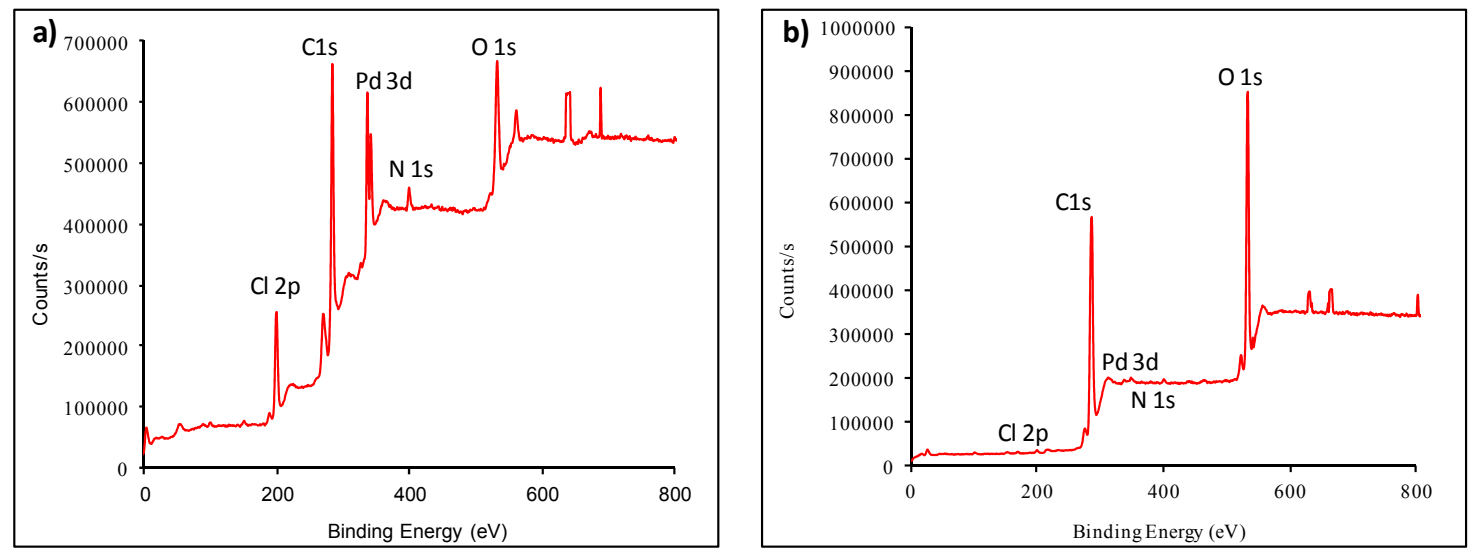

Figure 2. X-ray photoelectron spectroscopy (XPS) full spectra of: (a) 1; (b) 1-GO. 


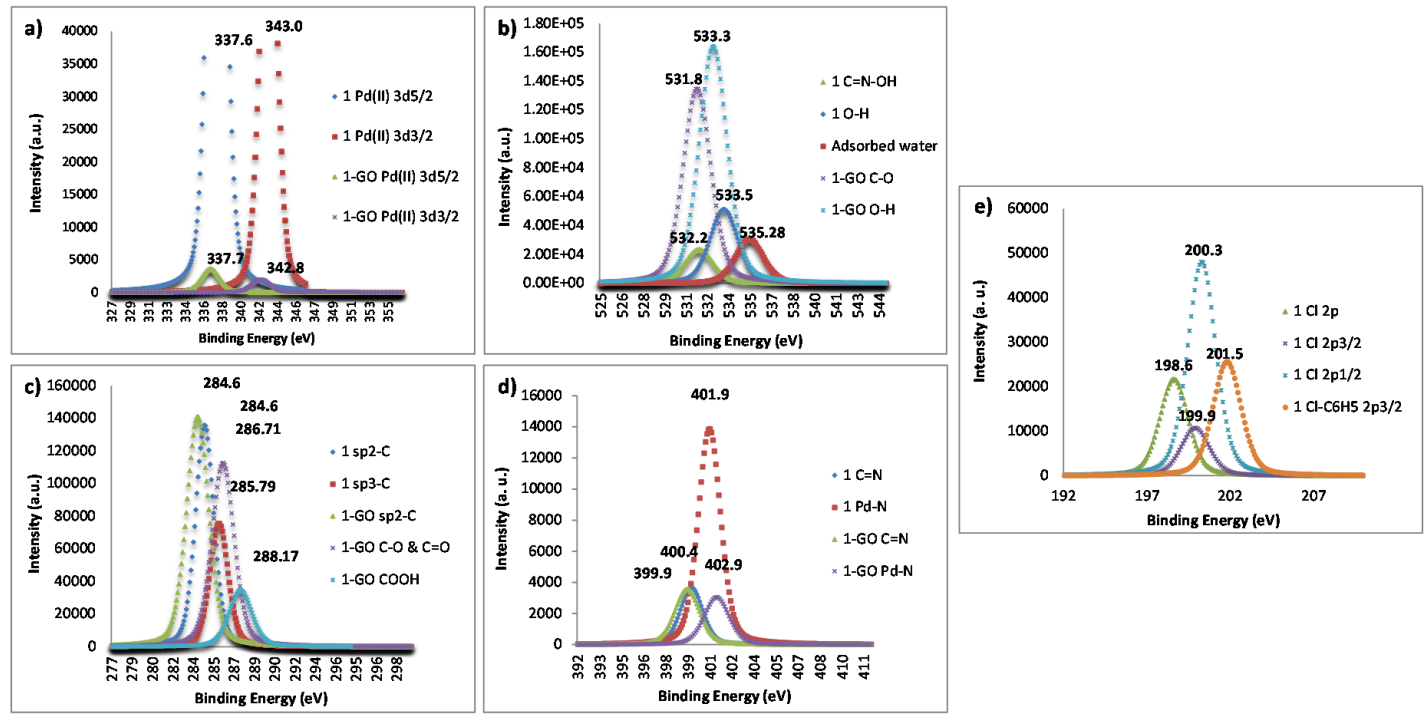

Figure 3. XPS spectra of 1 and 1-GO: (a) Pd3d; (b) O1s; (c) C1s; (d) N1s; (e) Cl2p, and deconvoluted peaks (\%) for Pd3d, C1s, O1s, N1s and Cl2p core levels.

Thermogravimetric analysis (TGA) of $\mathbf{1}$ (line blue), GO (black), and 1-GO (line red) was next performed (Figure 4). As shown, palladacycle 1 presents a $39 \%$ mass loss below $300{ }^{\circ} \mathrm{C}$ which corresponds with the degradation of the $4,4^{\prime}$-dichlorobenzophenone oxime. On the other hand, regarding the support, GO exhibited around a $13 \%$ mass loss below $100{ }^{\circ} \mathrm{C}$ and almost a $27 \%$ loss at $210{ }^{\circ} \mathrm{C}$ resulting from the removal of the labile oxygen-containing functional groups and $\mathrm{H}_{2} \mathrm{O}$. Finally, 1-GO exhibited a $28 \%$ mass loss at $200{ }^{\circ} \mathrm{C}$ due to the loss of the carbonaceous oxygenated species from GO and the loss of the organic ligand of the palladacycle. A final and significant common drop in mass was observed for the three materials around at $925^{\circ} \mathrm{C}$ connected with the pyrolysis of the carbon skeletons (Figure 4). According to the TGA, the Pd content for catalyst 1-GO (measured over different material batches) was between $1.35 \%$ to $2 \%$ which slightly differs from the content obtained from the more accurate ICP-OES technique $(1.10 \% \mathrm{Pd})$.

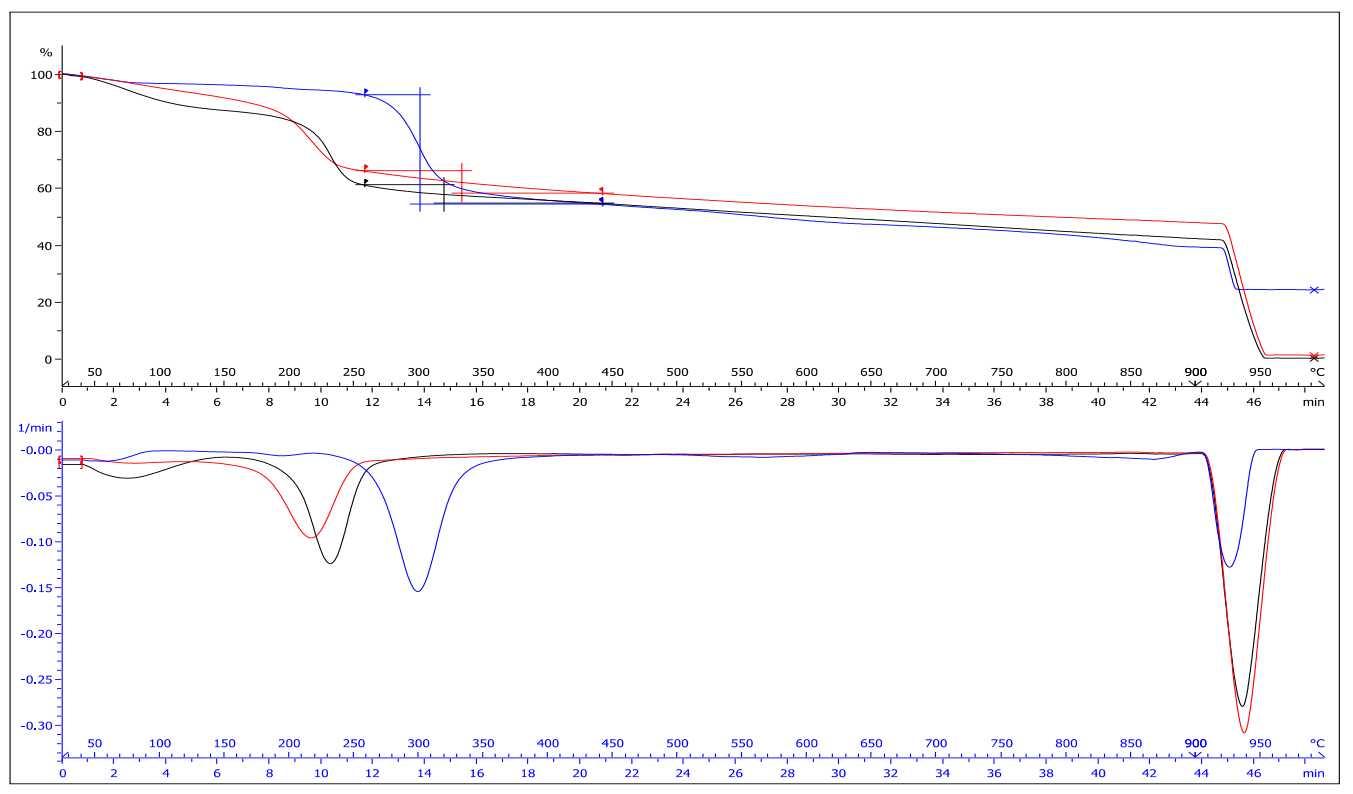

Figure 4. Thermogravimetric analysis (TGA) of $\mathbf{1}$ (line blue), GO (black), and 1-GO (line red). 
Catalyst 1-GO was also characterized by solid UV-vis spectroscopy. As depicted in Figure 5, 4,4'-dichlorobenzophenone oxime (EtOH solution) showed the characteristic absorption $\mathrm{C}$ band at $265 \mathrm{~nm}$. This absorption band was slightly blue shifted to $261 \mathrm{~nm}$ for palladacycle 1, which also exhibited the specific metal-to-ligand charge transfer band at about $357 \mathrm{~nm}$. As shown in the UV-vis absorption spectra, graphene oxide exhibited two absorption peaks, a maximum at $230 \mathrm{~nm}$ corresponding to $\pi / \pi^{*}$ transitions of aromatic $C-C$ bonds, and a shoulder at $293 \mathrm{~nm}$ attributed to $\mathrm{n} / \pi^{*}$ transitions of $\mathrm{C}=\mathrm{O}$ bonds [74]. Finally, in the UV-vis spectrum of 1-GO, the absorption $\mathrm{C}$ band from the palladacycle at $262 \mathrm{~nm}$ could be detected (Figure 5).

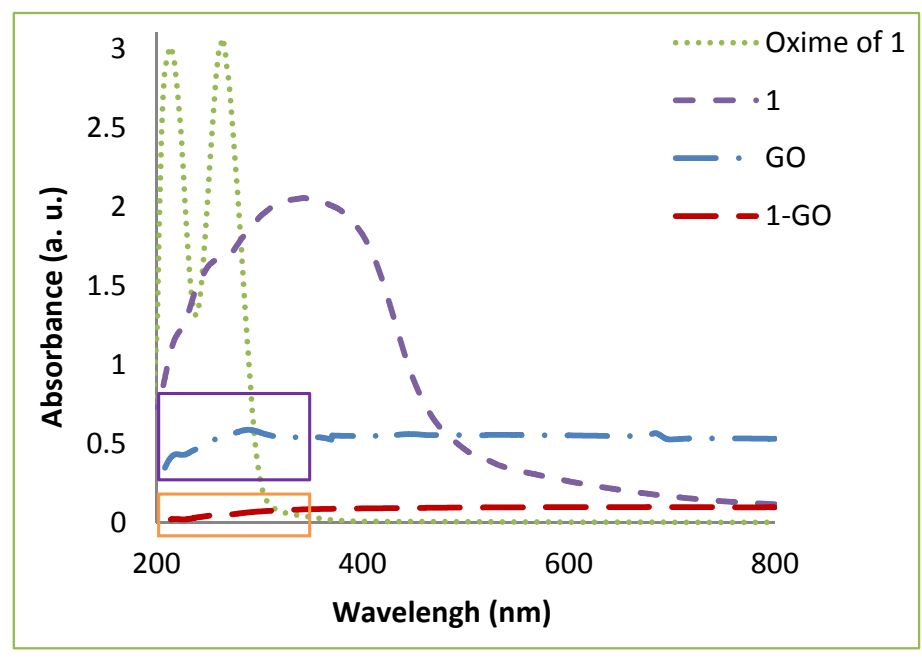

Figure 5. UV-Vis spectra of: 4,4'-dichlorobenzophenone oxime (EtOH solution), palladacycle 1 (solid state), GO (solid state), and 1-GO (solid state).

Palladacycles 1 and 2 have been demonstrated by our group to be very active precatalysts in the Suzuki-Miyaura reaction under organic [75] and aqueous conditions [76]. On the other hand, the amphiphilic character of GO (hydrophilic edges and hydrophobic basal plane) [77] should be beneficial in aqueous processes, converting this material in a potential phase-transfer catalyst. Thus, the synthesized materials 1-GO, 2-GO, and 3-GO were tested as precatalysts in the aqueous Suzuki-Miyaura cross-coupling between 4-bromoanisole and phenylboronic acid at room temperature under low loading conditions $(0.02 \mathrm{~mol} \% \mathrm{Pd})$ (Table 1$)$. Initially, we demonstrated that GO (2 wt \%) was not active in the cross-coupling process (Table 1, entry 1). As depicted in entries 2-4, the non-supported palladacycles 1-3 afforded 4-methoxybiphenyl (4) with high yields after $20 \mathrm{~h}(83,80$, and $99 \%$, respectively). Similar results were obtained for the supported catalysts 1-GO (85\%) and 3-GO $(82 \%)$ in the cross-coupling reaction, while catalyst 2-GO afforded 4 in a lower $69 \%$ conversion (Table 1, entries 5-7). In order to compare catalytic activities under the studied reaction conditions, Herrmann's catalyst (5) (Herrmann's catalyst was purchased from Aldrich (Madrid, Spain)) was also supported in GO following immobilization method B (Scheme 1) to afford catalyst 5-GO with a 3.22\% of Pd content according to the ICP-OES analysis (see SI for the synthesis and characterization data). As depicted in entries 8 and 9, both 5 and 5-GO afforded 4-methoxybiphenyl with good conversion, showing similar catalytic activities than the rest of the tested palladacyclic catalysts. 
Table 1. Suzuki-Miyaura reaction. Catalyst study.

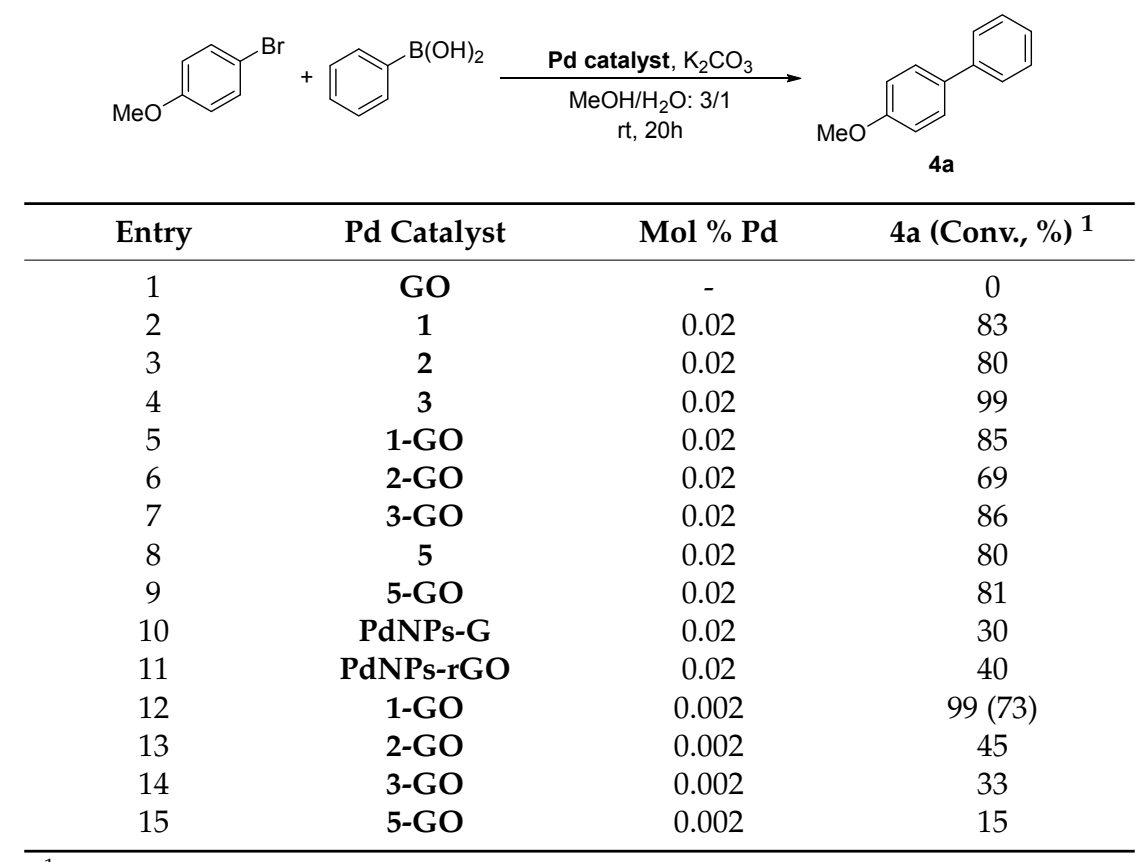

${ }^{1}$ Reaction conversion towards 4 determined by GC analysis. Isolated yield in brackets.

The activity of immobilized palladium nanoparticles on graphene nanoplatelets (PdNPs-G) and reduced graphene oxide (PdNPs-rGO) as a catalyst was also evaluated in the model Suzuki-Miyaura coupling. As previously described, these supported catalysts, obtained from NanoInnova Technologies S.L., have shown good activity in the Suzuki cross-coupling of potassium aryltrifluoroborates with aryl halides [65]. However, under the studied conditions, these materials afforded 4-methoxybiphenyl (4) in a 30 and $40 \%$ conversion, respectively (Table 1, entries 10 and 11).

In view of the obtained results, it became evident that a reduction in the catalyst loading was mandatory to determine the most active catalyst in the model Suzuki cross-coupling. Thus, supported catalysts 1-GO, 2-GO, 3-GO, and 5-GO were tested reducing the catalyst loading down to $0.002 \mathrm{~mol} \%$ of Pd in order to test the limits of the new materials. As depicted in Table 1 (entries 12-15), only oxime-palladacycle-derived catalyst 1-GO was active enough to give 4-methoxybiphenyl in a good $73 \%$ isolated yield at room temperature.

Next, we performed a substrate scope using catalyst 1-GO under the optimized reaction conditions (Table 2). Initially, we checked the reactivity of different boron-derived nucleophiles with 4-bromoanisole (Table 2, entries 1-4), none of them being as active as the phenylboronic acid. Then, we confirmed the activity of the catalytic system using deactivated aryl bromides as electrophiles, since not only 4-bromoanisole but also 4-bromophenol afforded, after reaction with phenylboronic acid, the corresponding [1,1'-biphenyl]-4-ol in a $61 \%$ yield (Table 2 , entry 5 ). Both the activated 4-bromoacetophenone and the neutral bromobenzene reacted with phenylboronic acid and 4-tolylboronic acid to afford biphenyls $4 \mathrm{c}$ and $4 \mathrm{~d}$ in 66 and $94 \%$ yields, respectively. On the other hand, as depicted in entries 8 and 9, 1-GO seemed to be very sensitive towards the steric hindrance of the reactants since a $42 \%$ yield was obtained for the reaction between 2 -bromotoluene and phenylboronic acid (entry 9), while no reaction was observed when 4-bromoanisole reacted with (2,6-dimethylphenyl)boronic acid (Table 2, entry 9). Regarding the electronic nature of the nucleophile, the electron-rich 4 -tolylboronic acid afforded $4 \mathrm{~g}$ in a $68 \%$ yield after reaction with 4 -bromoanisole (Table 2, entry 10). On the contrary, the electron-poor 4-(trifluoromethyl)phenylboronic acid showed, as expected, a very low reactivity with the same deactivated electrophile giving biphenyl $4 \mathrm{~h}$ in a $12 \%$ yield (Table 2, entry 11). Finally, we could also perform a Suzuki alkenylation of 4-bromoanisole with styrylboronic acid, which afforded compound $4 \mathbf{i}$ in a $35 \%$ yield (Table 2, entry 12 ). 
Table 2. Suzuki coupling catalyzed by $\mathbf{1 - G O}{ }^{1}$.

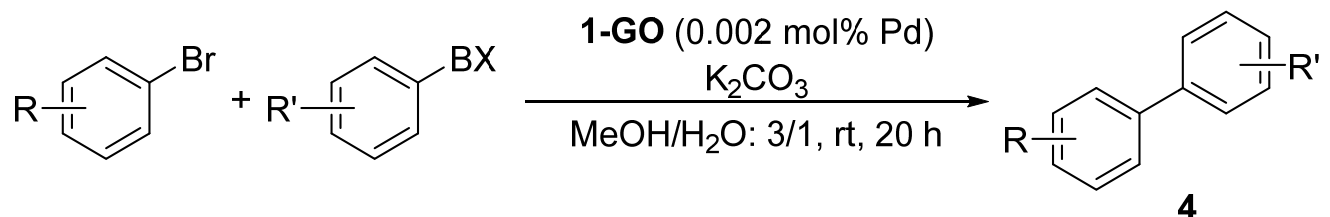

\begin{tabular}{cccccc}
\hline Entry & $\mathbf{R}$ & $\mathbf{R}^{\prime}$ & $\mathbf{B X}$ & $\mathrm{B}(\mathrm{OH})_{2}$ \\
\hline 1 & $4-\mathrm{OMe}$ & $\mathrm{H}$ & $\mathrm{BF}_{3} \mathrm{~K}$ \\
\hline 2 & $4-\mathrm{OMe}$ & $\mathrm{H}$ & $\mathrm{B}\left(\mathrm{OCMe}_{2}\right)_{2}$ \\
\hline 3 & $4-\mathrm{OMe}$ & $\mathrm{H}$ & \\
\hline 4 & $4-\mathrm{OMe}$ & $\mathrm{H}$ & $\mathrm{B}\left(\mathrm{OCOCH}_{2}\right)_{2} \mathrm{NMe}$
\end{tabular}

$6 \quad 4-\mathrm{Ac} \quad \mathrm{H} \quad \mathrm{B}(\mathrm{OH})_{2}$<smiles>C[C](C#N)c1ccc(-c2ccccc2)cc1</smiles>

4c

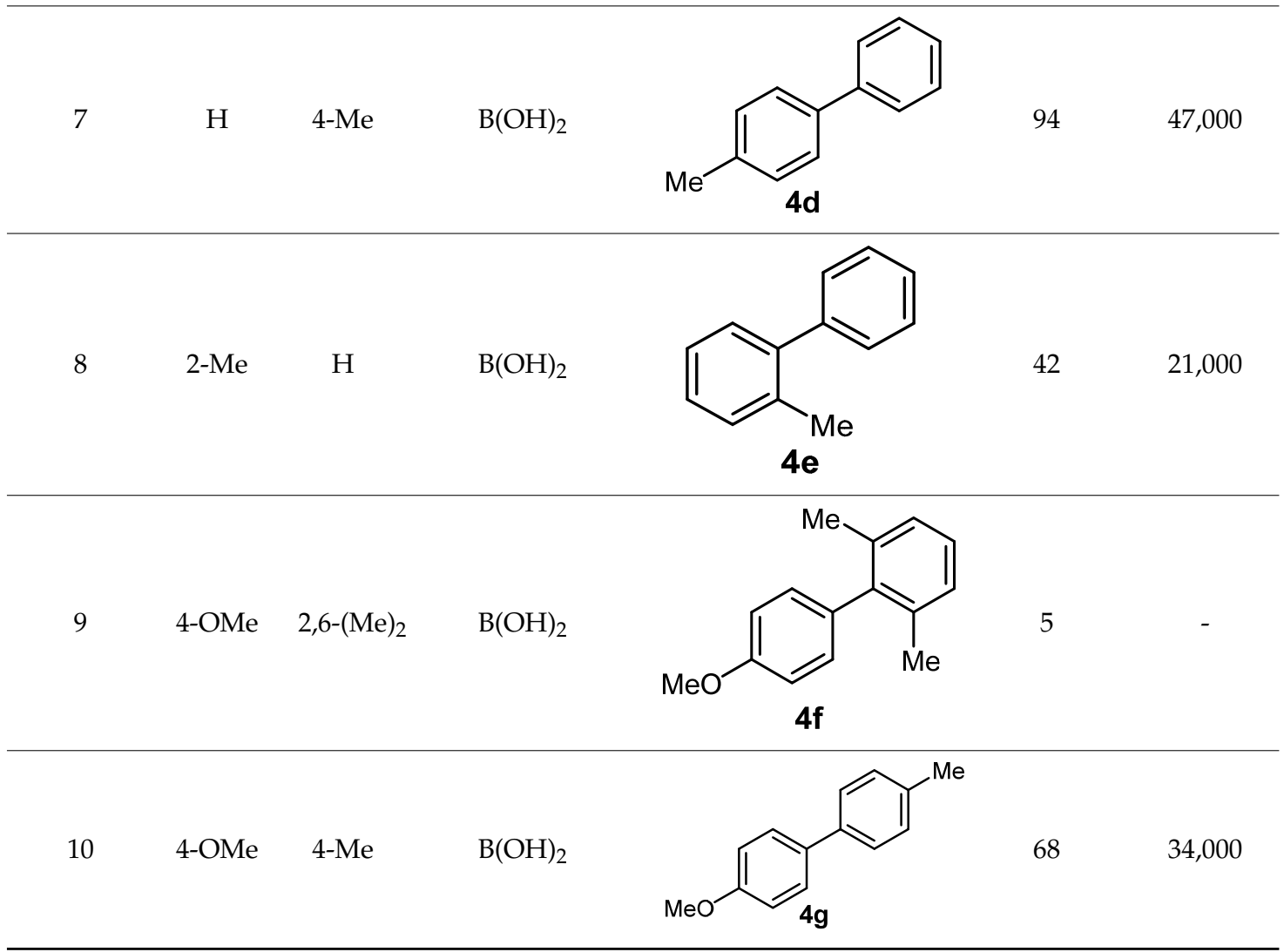


Table 2. Cont.

\begin{tabular}{|c|c|c|c|c|c|c|}
\hline Entry & $\mathbf{R}$ & $\mathbf{R}^{\prime}$ & BX & Product & ${\text { Yield }(\%)^{2}}^{2}$ & TON \\
\hline 11 & 4-OMe & $4-\mathrm{CF}_{3}$ & $\mathrm{~B}(\mathrm{OH})_{2}$ & & 12 & 6000 \\
\hline 12 & 4-OMe & -3 & $\mathrm{~B}(\mathrm{OH})_{2}$ & & 35 & 17,500 \\
\hline
\end{tabular}

${ }^{1}$ Reaction conditions: $\mathrm{ArBr}(1.25 \mathrm{mmol}, 1$ eq. $), \mathrm{ArB}(\mathrm{OH})_{2}(1.56 \mathrm{mmol}, 1.25$ eq. $), \mathrm{K}_{2} \mathrm{CO}_{3}(2.5 \mathrm{mmol}, 2$ eq. $)$, 1-GO
$\left(2 \times 10^{-3} \mathrm{~mol} \% \mathrm{Pd}\right) ;{ }^{2}$ Isolated yields after flash chromatography; ${ }^{3}$ Styrylboronic acid was used as nucleophile.

With respect to the active species involved in the Suzuki reaction employing 1-GO as a pre-catalyst, it is well-known that oxime palladacycles act as stable precursors to highly active and truly $\operatorname{Pd}(0)$ catalyst, usually generated after transmetallation by the activated boron nucleophile followed by a reductive elimination reaction of the aryl-ligated palladacycle [78]. The presence of water in the reaction medium, as demonstrated by Blackmond [79], would also play a key role in accelerating the initial formation of the monomeric active catalytic species. As commented above, palladium nanoparticles on graphene nanoplatelets (PdNPs-G, average nanoparticle size: $4.50 \mathrm{~nm}$ ) and reduced graphene oxide (PdNPs-rGO, average nanoparticle size: $10.9 \mathrm{~nm}$ ) have shown lower activity in the model Suzuki reaction under the optimized reaction conditions, probably due to the agglomeration of the nanoparticles under the reaction conditions. The slow release of the active Pd species from the oxime palladacycle in 1-GO, would account for the better activity of this material in the Suzuki reaction.

A simple recovery and reuse of transition-metal immobilized catalytic systems is highly desirable from both economic and environmental points of view. Therefore, a study of 1-GO recyclability was carried out on the model reaction, i.e., the coupling between 4-bromoanisole and phenylboronic acid using $0.1 \mathrm{~mol} \% \mathrm{Pd}$ as catalyst loading. After each cycle, the catalyst was easily separated from the reaction mixture by washing the crude reaction with a EtOAc $/ \mathrm{H}_{2} \mathrm{O}: 1 / 1$ solvent mixture and subsequent centrifugation (see SI, for details). As depicted in Scheme 2, catalyst 1-GO showed good catalytic activity for the two first reactions runs, decreasing the conversion of the reaction from the third cycle.<smiles>COc1ccc(Br)cc1</smiles>

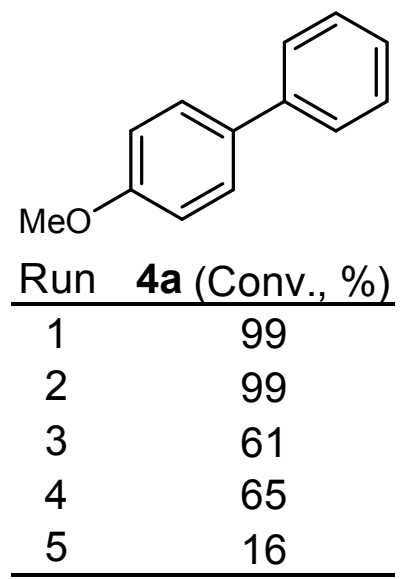

Scheme 2. 1-GO recyclability and yields in the Suzuki-Miyaura coupling in different reaction cycles. 
Figure 6 shows the reasons why 1-GO undergoes a loss of catalytic activity along the successive reaction cycles. The Pd3d X-ray photoelectron spectroscopy (XPS) spectrum (Figure 6a) indicated the presence of two different $\mathrm{Pd}(\mathrm{II})$ entities. The component at the higher binding energy was assigned to oxime palladacycle 1, while the component at the lower binding energy $[336.2(\operatorname{Pd} 3 \mathrm{~d} 5 / 2)$ and 341.8 $(\mathrm{Pd} 3 \mathrm{~d} 3 / 2) \mathrm{eV}]$ was assigned to PdO due to the surface oxidation of the Pd NPs generated from the palladacycle during the catalytic cycles [80]. C1s XPS analysis also showed a marked decrease of the oxygen content in 1-GO after the fifth run: Fresh 1-GO (O/C: 0.714); 1-GO after the fifth cycle $(\mathrm{O} / \mathrm{C}$ : $0.371)$. The low catalytic activity of palladium oxide, especially being agglomerated as demonstrated by the TEM analysis (Figure 6b), would account for the observed decrease of the catalytic activity of the 1-GO system. Also, inductively coupled plasma mass spectrometry (ICP-OES) analysis of the washings after the fifth run showed $67 \mathrm{ppb}$ of Pd leaching.
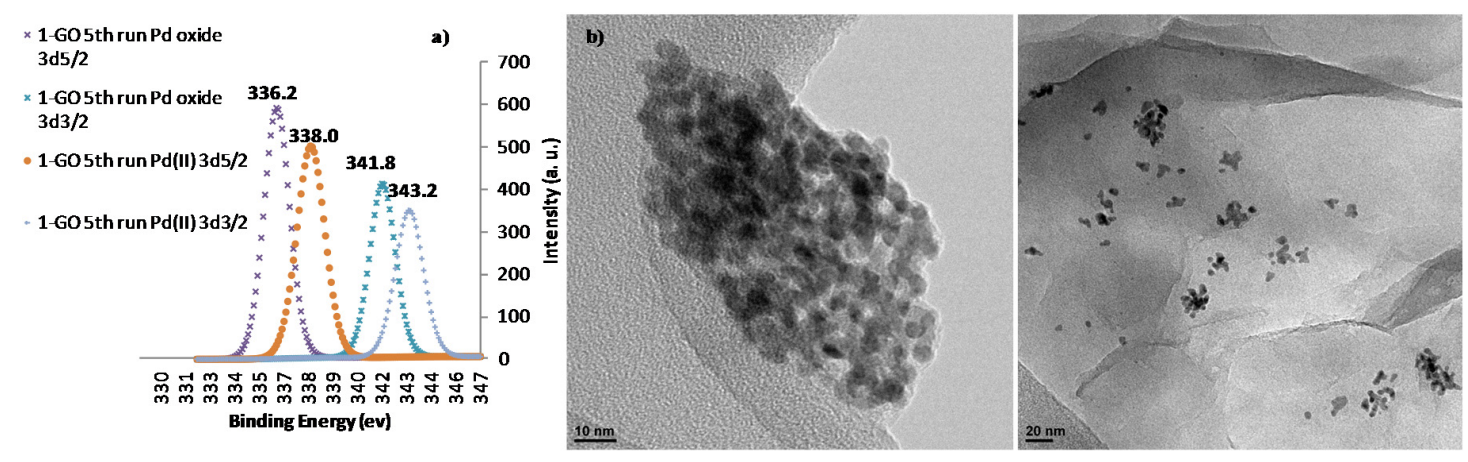

Figure 6. Analysis of 1-GO after five reaction cycles: (a) XPS Pd spectrum; (b) TEM images.

Oxime palladacycles are considered reservoirs of highly active palladium nanoparticles [66-68]. Usually, PdNps supported on graphene materials are prepared by reduction of a $\mathrm{Pd}$ salt or $\mathrm{Pd}$ catalyst in the presence of the corresponding carbonaceous support [45-62]. Then, we next turned our attention to the reduction of $\mathbf{1}$ with $\mathrm{NaBH}_{4}$ and the catalytic activity of the supported PdNPs was thus obtained. When unsupported palladacycle 1 was reduced with $\mathrm{NaBH}_{4}$ in the presence of GO (Scheme 3, Eq. a) [81], a carbonaceous material [Pd(0)-rGO] with an $8.40 \%$ Pd content (by ICP-OES analysis) was obtained. XPS analysis of this material showed a $75.8 \%$ content of $\operatorname{Pd}(0)$, which unfortunately suffered agglomeration during the reduction process as demonstrated by TEM analysis (Scheme 3 Eq. a). On the other hand, the reduction of 1-GO with $\mathrm{NaBH}_{4}$ (Scheme 3, Eq. b) afforded a material [Pd(II)-rGO] which, according to ICP-OES analysis, contained a 5.97\% Pd. XPS analysis of [Pd(II)-rGO] demonstrated the stability of palladacycle under these reduction conditions since $76.8 \%$ of 1 was not reduced. Both materials suffered a strong decrease of oxygen content as a consequence of the reduction of $\mathrm{GO}(\mathrm{O} / \mathrm{C}: 0.655)$ to $\mathrm{rGO}(\mathrm{O} / \mathrm{C}: 0.237-0.369)$.

We also studied the activity of $\mathbf{P d}(\mathbf{0})$-rGO and $\mathbf{P d}(\mathrm{II})$-rGO in the model Suzuki reaction between 4-bromoanisole and phenylboronic acid under the optimized reaction conditions $(0.002 \mathrm{~mol} \% \mathrm{Pd})$ (Scheme 4). As expected, Pd(0)-rGO was catalytically inactive in the process. On the other hand, Pd(II)-rGO afforded $4 \mathrm{a}$ in a $40 \%$ yield (Scheme 4). This result ratified the important amphiphilic effect of GO on the Suzuki coupling carried out under aqueous conditions. Palladacycle 1 was also immobilized over rGO following Method B (see SI), but the material thus obtained (1-rGO) only contained a $0.035 \%$ of Pd, according to the ICP-OES analysis. 


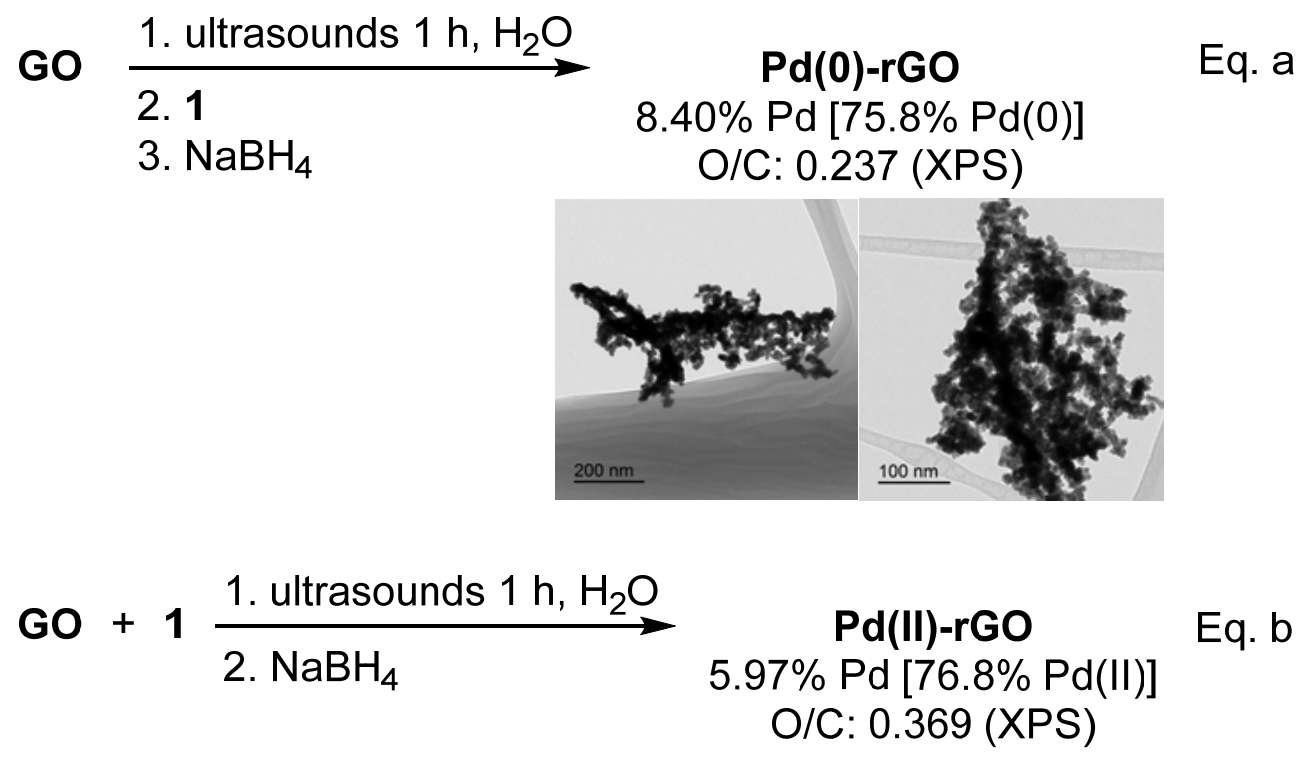

Scheme 3. Palladacycle reduction studies in the presence of GO.<smiles>COc1ccc(Br)cc1</smiles>

$\mathrm{rt}, 20 \mathrm{~h}$<smiles>COc1ccc(-c2ccccc2)cc1</smiles>

$\operatorname{Pd}(0)-$-rGO: $<5 \%$

Pd(II)-rGO: $40 \%$

Scheme 4. Suzuki coupling using rGO as a catalyst support.

\section{Materials and Methods}

\subsection{General}

Unless otherwise noted, all commercial reagents and solvents were used without further purification. ${ }^{1} \mathrm{H}-\mathrm{NMR}(300 \mathrm{MHz})$ and ${ }^{13} \mathrm{C}-\mathrm{NMR}(75 \mathrm{MHz})$ spectra were obtained on a Bruker AC-300, using $\mathrm{CDCl}_{3}$ as solvent and TMS (0.003\%) as reference, unless otherwise stated. Low-resolution mass spectra (MS) were recorded in the electron impact mode (EI, $70 \mathrm{eV}, \mathrm{He}$ as carrier phase) using an Agilent 5973 Network Mass Selective Detector spectrometer, being the samples introduced through a GC chromatograph Agilent 6890N equipped with a HP-5MS column [(5\%-phenyl)-methylpolysiloxane; length $30 \mathrm{~m}$; ID $0.25 \mathrm{~mm}$; film $0.25 \mathrm{~mm}$ ]. Analytical TLC was performed on Merck aluminum sheets with silica gel 60 F254. Silica gel $60(0.04-0.06 \mathrm{~mm})$ was employed for flash chromatography. The conversion of the reactions was determined by GC analysis on an Agilent 6890 N Network GC system. Centrifugations were carried out in a Hettich centrifuge (Universal 320, $6000 \mathrm{rpm}, 15 \mathrm{~min}$ ). ICP-MS analyses were performed on an Agilent 7700x equipped with HMI (high matrix introduction) and He mode ORS as standard. Elemental analyses were determined with a CHNS elemental micro analyzer with Micro detection system TruSpec LECO. X-ray Powder Diffraction (XRD) was performed in a Bruker D8-Advance with mirror Goebel (non-planar samples) with high temperature Chamber (up to $900{ }^{\circ} \mathrm{C}$ ), with a generator of $x$-ray KRISTALLOFLEX K 760-80F (power: $3000 \mathrm{~W}$, voltage: 20-60 KV and current: 5-80 mA) with a tube of RX with copper anode. X-ray photoelectron spectroscopy (XPS) was performed in a VG-Microtech Mutilab 3000 equipment equipped with a hemispherical electron analyzer with 9 channeltrons (with energy of passage of $(2-200 \mathrm{eV})$ and an X-ray radiation source 
with $\mathrm{Mg}$ and $\mathrm{Al}$ anodes. Transmission electron microscopy (TEM) was performed in JEOL Model JEM-2010. This microscope features an OXFORD X-ray detector model INCA Energy TEM 100 for microanalysis (EDS). The image acquisition camera is of the brand GATAN model ORIUS SC600. It is mounted on the axis with the microscope at the bottom and is integrated into the GATAN Digital Micrograph 1.80.70 image acquisition and processing program for GMS 1.8.0. The supported catalyst were sonicated in a ultrasons P-Selecta $(360 \mathrm{~W})$. Solid state UV-Vis spectroscopy was performed in a JASCO V-670 dual-beam UV-Vis/NIR spectrometer covering the wavelength range from 190 to $2700 \mathrm{~nm}$. The equipment has a single monochromator with double netting, one for the UV-Vis region (1200 grooves $/ \mathrm{mm}$ ) and one for the NIR region ( 300 grooves $/ \mathrm{mm}$ ). The detectors are a photomultiplier tube for the UV-Vis region and a PbS detector for the NIR region. The switching of both the detectors and the networks is automatically effected at a wavelength set by the user between 750 and $900 \mathrm{~nm}$. The sources used are a deuterium lamp (190 to $350 \mathrm{~nm}$ ) and a halogen lamp (330 to $2700 \mathrm{~nm}$ ). UV-Vis spectroscopy analysis of oxime precursor of catalyst 1 was performed in ethanol solution $(1.04 \mathrm{mg}$ of oxime in $20 \mathrm{~mL}$ of ethanol aproxymately) in a SHIMAZU UV-1603 spectrophotometer covering the wavelength range from 190 to $2700 \mathrm{~nm}$.

\subsection{Synthesis of Oxime Palladacycle $\mathbf{1}$}

A MeOH $(0.8 \mathrm{~mL})$ solution of the oxime derived from 4,4'-dichlorobenzophenone (1 eq), sodium acetate $(61.70 \mathrm{mg}, 0.752 \mathrm{mmol}, 1 \mathrm{eq})$ and $\mathrm{Li}_{2} \mathrm{PdCl}_{4}(1.5 \mathrm{~mL}$ of a $0.5 \mathrm{M}$ solution in $\mathrm{MeOH}, 1$ eq) was stirred at room temperature under argon atmosphere for 4 days. Then, water was added to precipitate the corresponding palladium complex and subsequently, the palladacycle was filtered and washed with water and hexane. Finally, the catalyst was dried under reduced pressure overnight giving oxime palladacycle 1 as a yellow solid ( $47 \%$ yield).

\subsection{Synthesis of 1-GO}

A $10 \mathrm{~mL}$ glass vessel was charged with GO $(200 \mathrm{mg})$ and $\mathbf{1}(45.89 \mathrm{mg})$. Then, anhydrous THF $(4 \mathrm{~mL})$ was added and the reaction mixture was sonicated for $1 \mathrm{~h}$. Afterwards, the reaction was stirred at room temperature for $48 \mathrm{~h}$. After this time, the catalyst was submitted to four washing (THF, $10 \mathrm{~mL}$ )-centrifugation (6000 rpm, $20 \mathrm{~min}$ ) cycles, with the solvent being eliminated after each cycle with a syringe equipped with a $4 \mathrm{~mm} / 0.2 \mu \mathrm{m}$ PTFE syringe filter. The residual solvent was completely removed under reduced pressure affording 1-GO ( $2 \%$ Pd by ICP-OES).

\subsection{Typical Procedure for the Suzuki-Miyaura Reaction}

A $10 \mathrm{~mL}$ glass vessel was charged with 1-GO $(0.002 \mathrm{~mol} \% \mathrm{Pd}, 0.198 \mathrm{mg})$, 4-bromoanisole $(156.5 \mu \mathrm{L}$, $1.25 \mathrm{mmol}, 1 \mathrm{eq}$ ), phenylboronic acid (190.20 mg, $1.56 \mathrm{mmol}, 1.25 \mathrm{eq}), \mathrm{K}_{2} \mathrm{CO}_{3}$ (345.50 mg, $2.5 \mathrm{mmol}$, 2 eq) and $\mathrm{MeOH} / \mathrm{H}_{2} \mathrm{O}: 3 / 1(3 \mathrm{~mL})$. The vessel was sealed with a pressure cap and the mixture was stirred at room temperature for $20 \mathrm{~h}$. Then, $\mathrm{H}_{2} \mathrm{O}(5 \mathrm{~mL})$ and EtOAc $(5 \mathrm{~mL})$ were added and the liquid mixture was filtered with cotton and extracted with EtOAc $(3 \times 10 \mathrm{~mL})$. The organic layers were dried over $\mathrm{MgSO}_{4}$ and concentrated under reduced pressure. The crude residue was purified by flash chromatography (silica gel, Hexane/EtOAc: $95 / 5$ ) to obtain $0.167 \mathrm{~g}$ of pure $4 \mathbf{a}$ (73\% yield).

\subsection{Typical Procedure for the Recovery of the Catalyst in the Suzuki-Miyaura Reaction}

Once the reaction was finished, the mixture was suspended and stirred for $15 \mathrm{~min}$ in a $10 \mathrm{~mL}$ mixture of EtOAc $/ \mathrm{H}_{2} \mathrm{O}: 1 / 1$. Then, this mixture was centrifuged $(6000 \mathrm{rpm}, 20 \mathrm{~min})$ and the solvent was eliminated using a syringe equipped with $4 \mathrm{~mm} / 0.2 \mu \mathrm{m}$ PTFE syringe filter. The washing/centrifugation sequence was repeated four additional times until no product was detected in the liquid phase by thin layer chromatography. The residual solvent was completely removed under reduced pressure affording the supported palladacycle catalyst which was directly used in the same tube with fresh reagents for the next run. This procedure was repeated for every cycle and the conversion of the reaction was determined by GC using decane as internal standard. 


\section{Conclusions}

We have synthesized and characterized new non-covalent supported oxime palladacycles on graphene oxide as efficient catalysts for the Suzuki-Miyaura coupling between aryl bromides and arylboronic acids. Catalyst 1-GO resulted very active for this process under aqueous conditions at room temperature under very low catalyst loadings $(0.002 \mathrm{~mol} \% \mathrm{Pd})$. Catalyst 1-GO can be recovered and reused with loss of catalytic activity after the second cycle due to the oxidation and metal agglomeration processes.

Supplementary Materials: The following are available online at www.mdpi.com/2073-4344/7/3/94/s1.

Acknowledgments: Financial support from the University of Alicante (UAUSTI16-03, UAUSTI16-10, VIGROB-173), the Spanish Ministerio de Economía, Industria y Competitividad (CTQ2015-66624-P) is acknowledged.

Author Contributions: Melania Gómez-Martínez performed the synthetic works. Alejandro Baeza and Diego A. Alonso designed the experiments of the project and supervised the whole studies reported in the manuscript. Melania Gómez-Martínez, Alejandro Baeza and Diego A. Alonso wrote the manuscript.

Conflicts of Interest: The authors declare no conflict of interest.

\section{References and Notes}

1. Diederich, F.; Stang, P.J. Metal-Catalyzed Cross-Coupling Reactions; Wiley-VCH: Weinheim, Germany, 1998.

2. Beller, M.; Bolm, C. Transition Metals for Organic Synthesis. Building Blocks and Fine Chemicals; Wiley-VCH: Weinheim, Germany, 1998.

3. Negishi, E. Handbook of Organopalladium Chemistry for Organic Synthesis; Wiley-Interscience: New York, NY, USA, 2002.

4. Miyaura, N. Cross-Coupling Reactions. A Practical Guide; Springer: Berlin, Germany, 2002.

5. Tsuji, J. Palladium Reagents and Catalysts. Innovations in Organic Synthesis; Wiley: Chichester, UK, 2004.

6. Beller, M.; Bolm, C. Transition Metals for Organic Synthesis. Building Blocks and Fine Chemicals, 2nd ed.; Wiley-VCH: Weinheim, Germany, 2004.

7. Diederich, F.; Stang, P.J. Metal-Catalyzed Cross-Coupling Reactions; Wiley-VCH: Weinheim, Germany, 2004.

8. Farina, V.; Miyaura, N.; Buchwald, S.L. Special Issue on Cross-Coupling Chemistry. Adv. Synth. Catal. 2004, 346, 1505-1879.

9. Negishi, E. Transition Metal-Catalyzed Organometallic Reactions that Have Revolutionized Organic Synthesis. Bull. Chem. Soc. Jpn. 2007, 80, 233-257. [CrossRef]

10. Dupont, J.; Pfeffer, M. Palladacycles: Synthesis, Characterization and Applications; Wiley-VCH: Weinheim, Germany, 2008.

11. Ratti, R. Palladacycles-Versatile Catalysts for Carbon-Carbon Coupling Reactions. Can. Chem. Trans. 2014, $2,467-488$.

12. Das, P.; Linert, W. Schiff base-derived homogeneous and heterogeneous palladium catalysts for the Suzuki-Miyaura reaction. Coord. Chem. Rev. 2016, 311, 1-23. [CrossRef]

13. Nájera, C. Oxime-Derived Palladacycles: Applications in Catalysis. ChemCatChem 2016, 8, 1865-1881. [CrossRef]

14. Bedford, R.B.; Cazin, C.S.J.; Hursthouse, M.B.; Light, M.E.; Pike, K.J.; Wimperis, S. Silica-supported imine palladacycles-Recyclable catalysts for the Suzuki reaction? J. Organomet. Chem. 2001, 633, 173-181. [CrossRef]

15. Baleizão, C.; Corma, A.; García, H.; Leyva, A. An oxime-carbapalladacycle complex covalently anchored to silica as an active and reusable heterogeneous catalyst for Suzuki cross-coupling in water. Chem. Commun. 2003, 606-607. [CrossRef]

16. Yu, K.; Sommer, W.; Weck, M.; Jones, C.W. Silica and polymer-tethered Pd-SCS-pincer complexes: Evidence for precatalyst decomposition to form soluble catalytic species in Mizoroki-Heck chemistry. J. Catal. 2004, 226, 101-110. [CrossRef]

17. Venkatesan, C.; Singh, A.P. Synthesis and characterization of carbometallated palladacycles over 3-hydroxypropyltriethoxysilyl-functionalized MCM-41. J. Catal. 2004, 227, 148-163. [CrossRef] 
18. Baleizão, C.; Corma, A.; García, H.; Leyva, A. Oxime Carbapalladacycle Covalently Anchored to High Surface Area Inorganic Supports or Polymers as Heterogeneous Green Catalysts for the Suzuki Reaction in Water. J. Org. Chem. 2004, 69, 439-446. [CrossRef] [PubMed]

19. Corma, A.; Das, D.; García, H.; Leyva, A. A periodic mesoporous organosilica containing a carbapalladacycle complex as heterogeneous catalyst for Suzuki cross-coupling. J. Catal. 2005, 229, 322-331. [CrossRef]

20. Mohamed, M.F.; Neverov, A.A.; Brown, R.S. An Immobilized Ortho-Palladated Dimethylbenzylamine Complex as an Efficient Catalyst for the Methanolysis of Phosphorothionate Pesticides. Inorg. Chem. 2009, 48, 1183-1191. [CrossRef] [PubMed]

21. Li, G.; Yang, H.; Lia, W.; Zhang, G. Rationally designed palladium complexes on a bulky N-heterocyclic carbene-functionalized organosilica: An efficient solid catalyst for the Suzuki-Miyaura coupling of challenging aryl chlorides. Green Chem. 2011, 13, 2939-2947. [CrossRef]

22. Farsadpour, S.; Ghoochany, L.T.; Shylesh, S.; Dörr, G.; Seifert, A.; Ernst, S.; Thiel, W.R. A Covalently Supported Pyrimidinylphosphane Palladacycle as a Heterogenized Catalyst for the Suzuki-Miyaura Cross Coupling. ChemCatChem 2012, 4, 401-407. [CrossRef]

23. Lu, F-H.; Yue, P.; Wang, X.-R.; Lu, Z.-L. Synthesis and immobilization of oxime-derived palladacycles as effective and reusable catalysts for the degradation of phosphorothionate pesticides. Inorg. Chem. Commun. 2013, 34, 19-22. [CrossRef]

24. Liu, H.; Li, T.; Xue, X.; Xua, W.; Wu, Y. The mechanism of a self-assembled Pd(ferrocenylimine)-Si compound-catalysed Suzuki coupling reaction. Catal. Sci. Technol. 2016, 6, 1667-1676. [CrossRef]

25. Lin, C.-A.; Luo, F.-T. Polystyrene-supported recyclable palladacycle catalyst for Heck, Suzuki and Sonogashira reactions. Tetrahedron Lett. 2003, 44, 7565-7568. [CrossRef]

26. Bedford, R.B.; Coles, S.J.; Hursthouse, M.B.; Scordia, V.J.M. Polystyrene-supported dicyclohexylphenylphosphine adducts of amine- and phosphite-based palladacycles in the Suzuki coupling of aryl chlorides. Dalton Trans. 2005, 991-995. [CrossRef] [PubMed]

27. Luo, F.-T.; Xue, C.; Ko, S.-L.; Shao, Y.-D.; Wu, C.-J.; Kuo, Y.-M. Preparation of polystyrene-supported soluble palladacycle catalyst for Heck and Suzuki reactions. Tetrahedron 2005, 61, 6040-6045. [CrossRef]

28. Corma, A.; Garcia, H.; Leyva, A. Comparison between polyethylenglycol and imidazolium ionic liquids as solvents for developing a homogeneous and reusable palladium catalytic system for the Suzuki and Sonogashira coupling. Tetrahedron 2005, 61, 9848-9854. [CrossRef]

29. Corma, A.; Garcia, H.; Leyva, A. Polyethyleneglycol as scaffold and solvent for reusable C-C coupling homogeneous Pd catalysts. J. Catal. 2006, 240, 87-99. [CrossRef]

30. Solodenko, W.; Mennecke, K.; Vogt, C.; Gruhl, S.; Kirschning, A. Polyvinylpyridine, a Versatile Solid Phase for Coordinative Immobilisation of Palladium Precatalysts-Applications in Suzuki-Miyaura Reactions. Synthesis 2006, 1873-1881.

31. Hershberger, J.C.; Zhang, L.; Lu, G.; Malinakova, H.C. Polymer-Supported Palladacycles: Efficient Reagents for Synthesis of Benzopyrans with Palladium Recovery. Relationship among Resin Loading, Pd:P Ratio, and Reactivity of Immobilized Palladacycles. J. Org. Chem. 2006, 71, 231-235. [CrossRef] [PubMed]

32. Mennecke, K.; Solodenko, W.; Kirschning, A. Carbon-Carbon Cross-Coupling Reactions under Continuous Flow Conditions Using Poly(vinylpyridine) Doped with Palladium. Synthesis 2008, 1589-1599. [CrossRef]

33. Alacid, E.; Najera, C. Kaiser oxime resin-derived palladacycle: A recoverable polymeric precatalyst in Suzuki-Miyaura reactions in aqueous media. J. Organomet. Chem. 2009, 694, 1658-1665. [CrossRef]

34. Islam, M.; Mondal, P.; Roy, A.S.; Tuhina, K. Catalytic oxidation of organic substrates using a reusable polystyrene-anchored orthometallated palladium (II) complex. J. Appl. Polym. Sci. 2010, 118, 52-62. [CrossRef]

35. Yang, Y.-C.; Toy, P.H. Self-Supported Ligands as a Platform for Catalysis: Use of a Polymeric Oxime in a Recyclable Palladacycle Precatalyst for Suzuki-Miyaura Reactions. Synlett 2014, 25, 1319-1324.

36. Cho, H.-J.; Jung, S.; Kong, S.; Park, S.-J.; Lee, S.-M.; Lee, Y.-S. Polymer-Supported Electron-Rich Oxime Palladacycle as an Efficient Heterogeneous Catalyst for the Suzuki Coupling Reaction. Adv. Synth. Catal. 2014, 356, 1056-1064. [CrossRef]

37. Sudheendran, M.; Eitel, S.H.; Naumann, S.; Buchmeiser, M.R.; Peters, R. Heterogenization of ferrocene palladacycle catalysts on ROMP-derived monolithic supports and application to a Michael addition. New J. Chem. 2014, 38, 5597-5607. [CrossRef] 
38. Karami, K.; Najvani, S.D.; Naeini, N.H.; Hervés, P. Palladium particles from oxime-derived palladacycle supported on $\mathrm{Fe}_{3} \mathrm{O}_{4}$ /oleic acid as a catalyst for the copper-free Sonogashira cross-coupling reaction. Chin. J. Catal. 2015, 36, 1047-1053. [CrossRef]

39. Gholinejad, M.; Razeghi, M.; Najera, C. Magnetic nanoparticles supported oxime palladacycle as a highly efficient and separable catalyst for room temperature Suzuki-Miyaura coupling reaction in aqueous media. RSC Adv. 2015, 5, 49568-49576. [CrossRef]

40. Karami, K.; Haghighat Naeini, N. Palladium nanoparticles supported on cucurbit[6]uril: An efficient heterogeneous catalyst for the Suzuki reaction under mild conditions. Appl. Organomet. Chem. 2015, 29, 33-39. [CrossRef]

41. Singh, V.; Ratti, R.; Kaur, S. Synthesis and characterization of recyclable and recoverable MMT-clay exchanged ammonium tagged carbapalladacycle catalyst for Mizoroki-Heck and Sonogashira reactions in ionic liquid media. J. Mol. Catal. A Chem. 2011, 334, 13-19. [CrossRef]

42. Karami, K.; Hashemi, S.; Dinari, M. Investigation of catalytic properties of two new orthopalladated complexes supported on montmorillonite: Synthesis, characterization and application in aerobic oxidation of alcohols. Appl. Organomet. Chem. 2017, in press. [CrossRef]

43. Hübner, S.; de Vries, J.G.; Farina, V. Why Does Industry Not Use Immobilized Transition Metal Complexes as Catalysts? Adv. Synth. Catal. 2016, 358, 3-25. [CrossRef]

44. Scheuermann, G.M.; Rumi, L.; Steurer, P.; Bannwarth, W.; Mülhaupt, R. Palladium Nanoparticles on Graphite Oxide and Its Functionalized Graphene Derivatives as Highly Active Catalysts for the Suzuki-Miyaura Coupling Reaction. J. Am. Chem. Soc. 2009, 131, 8262-8270. [CrossRef] [PubMed]

45. Siamaki, A.R.; Khder, A.E. R.S.; Abdelsayed, V.; El-Shall, M.S.; Gupton, B.F. Microwave-assisted synthesis of palladium nanoparticles supported on graphene: A highly active and recyclable catalyst for carbon-carbon cross-coupling reactions. J. Catal. 2011, 279, 1-11. [CrossRef]

46. Rumi, L.; Scheuermann, G.M.; Mülhaupt, R.; Bannwarth, W. Palladium Nanoparticles on Graphite Oxide as Catalyst for Suzuki-Miyaura, Mizoroki-Heck and Sonogashira Reactions. Helv. Chim. Acta 2011, 94, 966-976. [CrossRef]

47. Xiang, G.; He, J.; Li, T.; Zhuang, J.; Wang, X. Rapid preparation of noble metal nanocrystalsvia facile coreduction with graphene oxide and their enhanced catalytic properties. Nanoscale 2011, 3, 3737-3742. [CrossRef] [PubMed]

48. Machado, B.F.; Serp, P. Graphene-based materials for catalysis. Catal. Sci. Technol. 2012, 2, 54-75. [CrossRef]

49. Moussa, S.; Siamaki, A.R.; Gupton, B.F.; El-Shall, M.S. Pd-Partially Reduced Graphene Oxide Catalysts (Pd/PRGO): Laser Synthesis of Pd Nanoparticles Supported on PRGO Nanosheets for Carbon-Carbon Cross Coupling Reactions. ACS Catal. 2012, 2, 145-154. [CrossRef]

50. Ioni, Y.V.; Lyubimov, S.E.; Korlyukov, A.A.; Antipin, M.Y.; Davankov, V.A.; Gubin, S.P. Activity of palladium nanoparticles on graphene oxide in the Suzuki-Miyaura reaction. Russ. Chem. Bull., Int. Ed. 2012, 61, 1825-1827. [CrossRef]

51. Hu, J.; Wang, Y.; Han, M.; Zhou, Y.; Jiang, X.; Sun, P. A facile preparation of palladium nanoparticles supported on magnetite/s-graphene and their catalytic application in Suzuki-Miyaura reaction. Catal. Sci. Technol. 2012, 2, 2332-2340. [CrossRef]

52. Qu, K.; Wu, L.; Ren, J.; Qu, X. Natural DNA-Modified Graphene/Pd Nanoparticles as Highly Active Catalyst for Formic Acid Electro-Oxidation and for the Suzuki Reaction. ACS Appl. Mater. Inter. 2012, 4, 5001-5009. [CrossRef] [PubMed]

53. Shang, N.; Feng, C.; Zhang, H.; Gao, S.; Tang, R.; Wang, C.; Wang, Z. Suzuki-Miyaura reaction catalyzed by graphene oxide supported palladium nanoparticles. Catal. Commun. 2013, 40,111-115. [CrossRef]

54. Shang, N.; Gao, S.; Feng, C.; Zhang, H.; Wang, C.; Wang, Z. Graphene oxide supported N-heterocyclic carbene-palladium as a novel catalyst for the Suzuki-Miyaura reaction. RSC Adv. 2013, 3, 21863-21868. [CrossRef]

55. Hoseini, S.J.; Dehghani, M.; Nasrabadi, H. Thin film formation of Pd/reduced-graphene oxide and Pd nanoparticles at oil-water interface, suitable as effective catalyst for Suzuki-Miyaura reaction in water. Catal. Sci. Technol. 2014, 4, 1078-1083. [CrossRef]

56. Yamamoto, S.-I.; Kinoshita, H.; Hashimoto, H.; Nishina, Y. Facile preparation of Pd nanoparticles supported on single-layer graphene oxide and application for the Suzuki-Miyaura cross-coupling reaction. Nanoscale 2014, 6, 6501-6505. [CrossRef] [PubMed] 
57. Joshi, H.; Sharma, K.N.; Sharma, A.K.; Singh, A.K. Palladium-phosphorus/sulfur nanoparticles (NPs) decorated on graphene oxide: Synthesis using the same precursor for NPs and catalytic applications in Suzuki-Miyaura coupling. Nanoscale 2014, 6, 4588-4597. [CrossRef] [PubMed]

58. Bai, C.; Zhao, Q.; Li, Y.; Zhang, G.; Zhang, F.; Fan, X. Palladium Complex Immobilized on Graphene Oxide as an Efficient and Recyclable Catalyst for Suzuki Coupling Reaction. Catal. Lett. 2014, 144, 1617-1623. [CrossRef]

59. Park, J.H.; Raza, F.; Jeon, S.-J.; Kim, H.-I.; Kang, T.W.; Yim, S.; Kim, J.-H. Recyclable N-heterocyclic carbene/ palladium catalyst on graphene oxide for the aqueous-phase Suzuki reaction. Tetrahedron Lett. 2014, 55, 3426-3430. [CrossRef]

60. Movahed, S.K.; Esmatpoursalmani, R.; Bazgir, A. N-Heterocyclic carbene palladium complex supported on ionic liquid-modified graphene oxide as an efficient and recyclable catalyst for Suzuki reaction. RSC Adv. 2014, 4, 14586-14591. [CrossRef]

61. Lin, J.; Mei, T.; Lv, M.; Zhang, C.; Zhao, Z.; Wang, X. Size-controlled PdO/graphene oxides and their reduction products with high catalytic activity. RSC Adv. 2014, 4, 29563-29570. [CrossRef]

62. Pérez-Mayoral, E.; Calvino-Casilda, V.; Soriano, E. Metal-supported carbon-based materials: Opportunities and challenges in the synthesis of valuable products. Catal. Sci. Technol. 2016, 6, 1265. [CrossRef]

63. Fath, R.H.; Hoseini, S.J. Covalently cyclopalladium(II) complex/reduced-graphene oxide as the effective catalyst for the Suzuki-Miyaura reaction at room temperature. J. Organomet. Chem. 2017, 828, 16-23. [CrossRef]

64. Xue, Z.; Huang, P.; Li, T.; Qin, P.; Xiao, D.; Liu, M.; Chen, P.; Wu, Y. A novel "tunnel-like" cyclopalladated arylimine catalyst immobilized on graphene oxide nano-sheet. Nanoscale 2017, 9, 781-791. [CrossRef] [PubMed]

65. Gómez-Martínez, M.; Buxaderas, E.; Pastor, I.M.; Alonso, D.A. Palladium nanoparticles supported on graphene and reduced graphene oxide as efficient recyclable catalyst for the Suzuki-Miyaura reaction of potassium aryltrifluoroborates. J. Mol. Catal. A: Chem. 2015, 404, 1-7.

66. Alonso, D.A.; Botella, L.; Nájera, C.; Pacheco, M.C. Synthetic Applications of Oxime-Derived Palladacycles as Versatile Catalysts in Cross-Coupling Reactions. Synthesis 2004, 1713-1718.

67. Alacid, E.; Alonso, D.A.; Botella, L.; Nájera, C.; Pacheco, M.C. Oxime palladacycles revisited: Stone-stable complexes nonetheless very active catalysts. Chem. Rec. 2006, 6, 117-132. [CrossRef] [PubMed]

68. Alonso, D.A.; Nájera, C. Oxime-derived palladacycles as source of palladium nanoparticles. Chem. Soc. Rev. 2010, 39, 2891-2902. [CrossRef] [PubMed]

69. Alonso, D.A.; Nájera, C.; Pacheco, M.C. Oxime Palladacycles: Stable and Efficient Catalysts for Carbon-Carbon Coupling Reactions. Org. Lett. 2000, 2, 1823-1826. [CrossRef] [PubMed]

70. GO Was Supplied by Nanoinnova Technologies S.L. Available online: http://www.nanoinnova.com/ Product/Details/24 (accessed on 21 March 2017).

71. Singh, G.; Botcha, V.C.; Sutar, D.S.; Talwar, S.S.; Srinivasa, R.S.; Major, S.S. Graphite mediated reduction of graphene oxide monolayer sheets. Carbon 2015, 95, 843-851. [CrossRef]

72. Yu, B.; Wang, X.; Qian, X.; Xing, W.; Yang, H.; Ma, L.; Lin, Y.; Jiang, S.; Song, L.; Hu, Y.; et al. Functionalized graphene oxide/phosphoramide oligomer hybrids flame retardant prepared via in situ polymerization for improving the fire safety of polypropylene. RSC Adv. 2014, 4, 31782-31794. [CrossRef]

73. Lin, Y.; Pan, X.; Qi, W.; Zhang, B.; Su, D.S.J. Nitrogen-doped onion-like carbon: A novel and efficient metal-free catalyst for epoxidation reaction. Mater. Chem. A 2014, 2, 12475-12483. [CrossRef]

74. Paredes, J.I.; Villar-Rodil, S.; Martínez-Alonso, A.; Tascón, J.M.D. Au/graphene hydrogel: Synthesis, characterization and its use for catalytic reduction of 4-nitrophenol. Langmuir 2008, 24, 10560-10564. [CrossRef] [PubMed]

75. Alonso, D.A.; Nájera, C.; Pacheco, M.C. Highly Active Oxime-Derived Palladacycle Complexes for Suzuki-Miyaura and Ullmann-Type Coupling Reactions. J. Org. Chem. 2002, 67, 5588-5594. [CrossRef] [PubMed]

76. Botella, L.; Nájera, C. A Convenient Oxime-Carbapalladacycle-Catalyzed Suzuki Cross-Coupling of Aryl Chlorides in Water. Angew. Chem. Int. Ed. 2002, 41, 179-181. [CrossRef]

77. Kim, J.; Cote, L.J.; Kim, F.; Yuan, W.; Shull, K.R.; Huang, J. Graphene Oxide Sheets at Interfaces. J. Am. Chem. Soc. 2010, 132, 8180-8186. [CrossRef] [PubMed] 
78. Bedford, R.B.; Cazin, C.S.J.; Coles, S.J.; Gelbrich, T.; Horton, P.N.; Hursthouse, M.B.; Light, M.E. High-Activity Catalysts for Suzuki Coupling and Amination Reactions with Deactivated Aryl Chloride Substrates: Importance of the Palladium Source. Organometallics 2003, 22, 987-999. [CrossRef]

79. Rosner, T.; Le Bars, J.; Pfaltz, A.; Blackmond, D.G. Kinetic Studies of Heck Coupling Reactions Using Palladacycle Catalysts: Experimental and Kinetic Modeling of the Role of Dimer Species. J. Am. Chem. Soc. 2001, 123, 1848-1855. [CrossRef] [PubMed]

80. Wang, L.J.; Zhang, J.; Zhao, X.; Xu, L.L.; Lyu, Z.Y.; Laia, M.; Chen, W. Palladium nanoparticle functionalized graphene nanosheets for $\mathrm{Li}-\mathrm{O}_{2}$ batteries: Enhanced performance by tailoring the morphology of the discharge product. RSC Adv. 2015, 5, 73451-73456. [CrossRef]

81. Chua, C.K.; Pumera, M. Chemical reduction of graphene oxide: A synthetic chemistry viewpoint. Chem. Soc. Rev. 2014, 43, 291-312. [CrossRef] [PubMed]

(C) 2017 by the authors. Licensee MDPI, Basel, Switzerland. This article is an open access article distributed under the terms and conditions of the Creative Commons Attribution (CC BY) license (http:/ / creativecommons.org/licenses/by/4.0/). 